\title{
Лекарственно-индуцированная дистония
}

\author{
Остроумова Т.М. ${ }^{1}$, Толмачева В.А. ${ }^{1}$, Остроумова О.Д., ${ }^{1,2}$, Парфенов В.А.

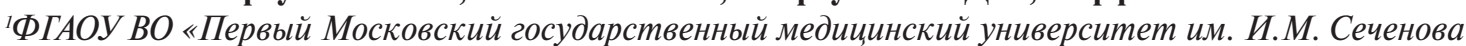 \\ Минздрава России (Сеченовский Университет), Москва; ${ }^{2}$ ФБОУ ДПО «Российская медицинская \\ академия непрерывного профессионального образования Минздрава России, Москва \\ 'Россия, 119021, Москва, ул. Россолимо, 11, стр. 1; ${ }^{2}$ Россия, 125993, Москва, ул. Баррикадная, 2/1, стр. 1
}

\begin{abstract}
Лекарственно-индуцированная дистония (ЛИД) является редко диагностируемой нежелательной побочной реакцией (НПР) достаточно большого количества лекарственных средств (ЛС). Острая ЛИД (ОЛИД) возникает вскоре после начала приема ЛС или увеличения его дозы, а также при переходе с одного антипсихотического препарата на другой, особенно на инбекционную форму. Тардивная ЛИД (ТЛИД) развивается спустя несколько месяцев или лет после начала приема ЛС либо через 3 мес после прекращения терапии. Диагноз ТЛИД основывается на сохранении дистонического гиперкинеза дольше 1 мес, факте приема блокатора дофаминовых рецепторов и отсутствия других причин ее развития. Факторами риска ЛИД являются мужской пол, молодой возраст (до 30 лет), дистонические реакции в анамнезе, гипокальциемия, употребление алкоголя одновременно с приемом препарата. Наиболее часто ЛИД ассоциирована с терапией антипсихотиками, метоклопрамидом, антидепрессантами, противоэпилептическими ЛС. В лечении ОЛИД эффективно использование коротким курсом антихолинергических препаратов (бензотропин, дифенгидрамин). При лечении ТЛИД применяют антихолинергические препараты, атипичные антипсихотики (клозапин, кветиапин), бензодиазепины, мышечные релаксанты (баклофен), препараты, ингибирующие обратный захват дофамина (тетрабеназин). В профилактике ЛИД крайне важны осведомленность врача о возможности данной НПР и выбор ЛС с наименьшим риском развития ЛИД.
\end{abstract}

Ключевые слова: экстрапирамидные нарушения; лекарственно-индуцированные экстрапирамидные нарушения; острая дистония; тардивная дистония; лекарственно-индуцированная дистония; нежелательные побочные реакции.

Контакты: Ольга Дмитриевна Остроумова; ostroumova.olga@mail.ru

Для ссылки: Остроумова ТМ, Толмачева ВА, Остроумова ОД, Парфенов ВА. Лекарственно-индуцированная дистония. Неврология, нейропсихиатрия, психосоматика. 2020;12(5):4-8. DOI: 10.14412/2074-2711-2020-5-4-8

\author{
Drug-induced dystonia \\ Ostroumova T.M. ${ }^{1}$, Tolmacheva V.A. ${ }^{1}$, Ostroumova O.D. ${ }^{1,2}$, Parfenov V.A. ${ }^{1}$ \\ ${ }^{1}$ I.M. Sechenov First Moscow State Medical University (Sechenov University), Ministry of Health of Russia, Moscow; \\ ${ }^{2}$ Russian Medical Academy of Continuing Professional Education, Ministry of Health of Russia, Moscow \\ ${ }^{1}$ 11, Rossolimo St., Build. 1, Moscow 119021, Russia; 22/1, Barrikadnaya St., Build. 1, Moscow 125993, Russia
}

Drug-induced dystonia (DID) is a rarely diagnosed adverse reaction to a sufficiently large number of drugs. Acute DID (ADID) occurs soon after starting to take a drug or raising its dose, and switching from one antipsychotic medication to another, especially to its injectable dosage form. Tardive DID (TDID) develops a few months or years after starting drug intake or 3 months after stopping therapy. The diagnosis of TDID is based on the persistence of dystonic hyperkinesis for more than 1 month, the use of a dopamine receptor blocking agent, and the absence of other causes of its development. The risk factors for DID are male sex; young age (less than 30 years of age); a history of dystonic reactions; hypocalcemia, alcohol use while taking the drug. DID is most commonly related to therapy with antipsychotics, metoclopramide, antidepressants, and antiepileptic drugs. The short-term use of anticholinergic drugs (benzotropin, diphenhydramine) is effective in treating ADID. Anticholinergic drugs and atypical antipsychotics (clozapine, quetiapine), benzodiazepines, muscle relaxants (baclofen), and dopamine reuptake inhibitors (tetrabenazine) are used to treat TDID. To prevent DID, it is very important that a physician should be aware of that this unwanted adverse reaction may occur and that a drug with the lowest risk for DID should be chosen.

Keywords: extrapyramidal disorders; drug-induced extrapyramidal disorders; acute dystonia; tardive dystonia; drug-induced dystonia; adverse reactions.

Contact: Olga Dmitrievna Ostroumova; ostroumova.olga@mail.ru

For reference: Ostroumova TM, Tolmacheva VA, Ostroumova OD, Parfenov VA. Drug-induced dystonia. Nevrologiya, neiropsikhiatriya, psikhosomatika $=$ Neurology, Neuropsychiatry, Psychosomatics. 2020;12(5):4-8. DOI: 10.14412/2074-2711-2020-5-4-8

Лекарственно-индуцированная дистония (ЛИД) является редко диагностируемой нежелательной побочной реакцией (НПР) достаточно большого количества лекарственных средств (ЛС) [1].

\section{Клинические проявления}

Острая ЛИД (ОЛИД) возникает вскоре после начала приема ЛС или увеличения его дозы, а также при переходе с одного антипсихотического препарата на другой, осо- 
бенно на инъекционную форму [1]. У половины пациентов первые симптомы ОЛИД развиваются через 2-5 сут от начала приема ЛС $[1,2]$. Дистонические гиперкинезы бывают различной тяжести, затрагивают любые анатомические области и, как правило, болезненны [1]. Самыми распространенными формами являются орофациальная, туловищная и цервикальная дистония (ЦД). Однако классическими проявлениями ОЛИД считаются окулогирные кризы (содружественное отклонение глазных яблок вверх или в сторону), длящиеся от нескольких минут до нескольких часов, опистотонус или экстензорная аксиальная дистония (непроизвольное отклонение головы, шеи и спины назад), а также оромандибулярная дистония (насильственные сокращения мышц нижней челюсти, затрудняющие закрывание или открывание рта) [1, 2]. Кроме этого, могут наблюдаться блефароспазм, тризм, ларингеальный спазм, протрузия языка и дыхательная дистония. Симптомы обычно болезненны и усиливаются при ходьбе, форсированном дыхании, разговоре, глотании. В тяжелых случаях, например при ларингоспазме, ОЛИД является жизнеугрожающим состоянием. Также выраженное сокращение мышц может привести к рабдомиолизу. Возникновение причудливых поз иногда ошибочно принимают за истерическую реакцию; поскольку дистония нередко возникает на фоне психического заболевания, она может быть ошибочно расценена как кататония. В отличие от пациентов с кататонией, пациенты с ОЛИД активно предъявляют жалобы и просят помощи. К сожалению, после перенесенного эпизода острой дистонии такие пациенты нередко отказываются от лечения основного психического заболевания. В случае повышения температуры тела, развития генерализованной ригидности, нарушения сознания, нестабильности со стороны сердечнососудистой и дыхательной систем диагностируют злокачественный нейролептический синдром [1].

Тардивную ЛИД (ТЛИД) стали выделять как самостоятельную нозологическую единицу в 1982 г., после того как R.E. Burke и соавт. [3] описали 42 больных с этим расстройством.

ТЛИД развивается спустя несколько месяцев или лет после начала приема ЛС либо через 3 мес после прекращения терапии [1, 2]. Диагноз ТЛИД основывается на сохранении дистонического гиперкинеза более 1 мес, факте приема блокатора дофаминовых рецепторов и отсутствии других причин развития дистонии (например, генетических форм дистонии, повреждения базальных ганглиев и др.) [1]. В отличие от ОЛИД, симптомы ТЛИД развиваются исподволь в течение недель или месяцев. Ремиссии не характерны. Симптомы могут не сопровождаться болью и быть изолированными в одной части тела или же распространяться на другие части тела и даже приобретать генерализованный характер (более типично для молодых людей). Пациенты нередко отмечают усиление выраженности симптомов в зависимости от эмоционального состояния, что приводит к вариабельности проявлений гиперкинеза в течение суток.

Цервикальная ТЛИД крайне схожа с идиопатической ЦД - непроизвольные мышечные сокращения приводят к формированию патологического положения головы и шеи, которое может сопровождаться тремором. В отличие от идиопатической ЦД, при которой чаще наблюдается тор- тиколлис, при тардивной ЦД чаще встречается ретроколлис. Степень клинического проявления варьирует от незначительного отклонения до выраженного, может сопровождаться болью и дистоническим дрожанием.

Сочетание оромандибулярной дистонии и блефароспазма напоминает синдром Мейжа. Тардивная оромандибулярная дистония (ОМД) включает трудности открывания и закрывания рта и нарушает жевание, речь и глотание. В структуре закрывательной формы ОМД нередко наблюдается бруксизм. Одной из форм аксиальной дистонии, ассоциированной с лечением нейролептиками, является синдром Пизанской башни - непроизвольное сгибание туловища в сторону (латерофлексия) [4]. Этот синдром более характерен для пожилых пациентов, чаще женщин, принимающих комбинацию антипсихотических препаратов, а также пациентов с органическими заболеваниями мозга, такими как деменция [5]. Синдром Пизанской башни может возникать как остро, так и отсроченно. В отличие от тардивной дистонии, выраженность синдрома уменьшается вплоть до исчезновения при прекращении приема индуцировавшего его ЛС. Вследствие этого синдром Пизанской башни можно считать атипичным вариантом тардивной дистонии. Редко у пациентов с тардивной дистонией может наблюдаться жизнеугрожающее состояние, сопровождающееся тяжелыми дистоническими спазмами, которые приводят к рабдомиолизу, миоглобинурии и острой почечной недостаточности.

\section{Рacпространенность и факторы риска}

Оценка распространенности ЛИД затруднительна в связи с большой гетерогенностью сопутствующих факторов риска, групп ЛС и их дозировок. Так, у пациентов, получавших антипсихотики, она может достигать 5\% [6]. Среди лиц, которым был впервые назначен антипсихотик, частота встречаемости ОЛИД варьирует в пределах 34-60\% [7]. Факторами риска ЛИД являются мужской пол, молодой возраст (до 30 лет), дистонические реакции в анамнезе, гипокальциемия, одновременное с приемом ЛС употребление алкоголя [6, 8].

Лекарственные препараты, ассоциированные с развитием Лид, и механизмы их развития

Различные ЛС, ассоциированные с развитием ЛИД, а также возможные механизмы их развития представлены в таблице.

\section{Антипсихотики}

Наиболее известна связь ЛИД с применением антипсихотиков в связи с их способностью связываться с дофаминовыми D2-рецепторами полосатого тела. На фоне приема ЛС из группы антипсихотиков возможно развитие как ОЛИД, так и ТЛИД. ЛИД также могут отмечаться на фоне отмены антипсихотиков $[1,9]$. В проспективном исследовании [10] (246 пациентов с острым психозом, не получавших ранее терапию антипсихотиками) ОЛИД на фоне применения рисперидона (средняя доза 3,2 мг) возникла в 26,4\% случаев, что статистически значимо не отличалось от частоты ее развития у больных, получавших галоперидол $(34,5 \%)$. В метаанализе рандомизированных контролируемых исследований частота встречаемости ОЛИД у больных моложе 18 лет, получав- 
ших арипипразол, статистически значимо не отличалась от таковой плацебо [11]. В метаанализе Кокрейновских систематических обзоров [12] ОЛИД на фоне приема оланзапина, кветиапина и зипрасидона встречалась реже, чем при лечении галоперидолом и хлорпромазином. пентином [23] и карбамазепином [24]. Описаны случаи развития как ОЛИД [24], так и ТЛИД [25] у детей и подростков на фоне применения карбамазепина. Имеются описания клинических случаев развития ОЛИД у пожилых пациентов, получавших одновременно габапентин и про-

\section{Метоклопрамид}

При приеме метоклопрамида возможно развитие различных экстрапирамидных нарушений, в том числе, хотя и достаточно редко, ЛИД. Распространенность ЛИД выше у детей и пожилых пациентов и может достигать 25\% [13]. Риск развития ОЛИД у детей в 6 раз выше по сравнению со взрослыми пациентами [14].

\section{Антидепрессанты}

ЛИД являются довольно редкой НПР при терапии антидепрессантами. Так, по данным австрийского исследования, в котором анализировались экстрапирамидные нарушения на фоне терапии антидепрессантами у пациентов с психическими заболеваниями, за период с 1993 по 2015 г. ЛИД развилась только у трех из 243588 пациентов [15].

ЛИД могут развиваться на фоне достаточно большого количества ЛС (см. таблицу). В доступной литературе имеются в основном описания клинических случаев данной НПР у пациентов с сопутствующими психическими заболеваниями [7]. Чаще всего ОЛИД связаны с применением различных ЛС из группы селективных ингибиторов обратного захвата серотонина [15]. ОЛИД на фоне применения флуоксетина описаны в основном у пациентов, получавших сопутствующую терапию антипсихотиками [16]. На фоне применения трициклических антидепрессантов описаны ОЛИД у детей, получавших имипрамин для лечения ночного энуреза [17], и ТЛИД у молодых мужчин, получавших амитриптилин в дозе 50 мг для лечения депрессии $[18,19]$. Также описаны ОЛИД после приема селективного ингибитора обратного захвата серотонина и норадреналина венлафаксина [20, 21].

\section{раты}

\section{Противоэпилептические препа-}

В проспективном исследовании ЛИД были выявлены у четырех из 201 пациента с эпилепсией, получавшего антиконвульсанты [22]. ЛИД потенциально могут быть вызваны габа-
ЛС, прием которых ассоциирован с развитием ЛИД

$[1,6-32]$

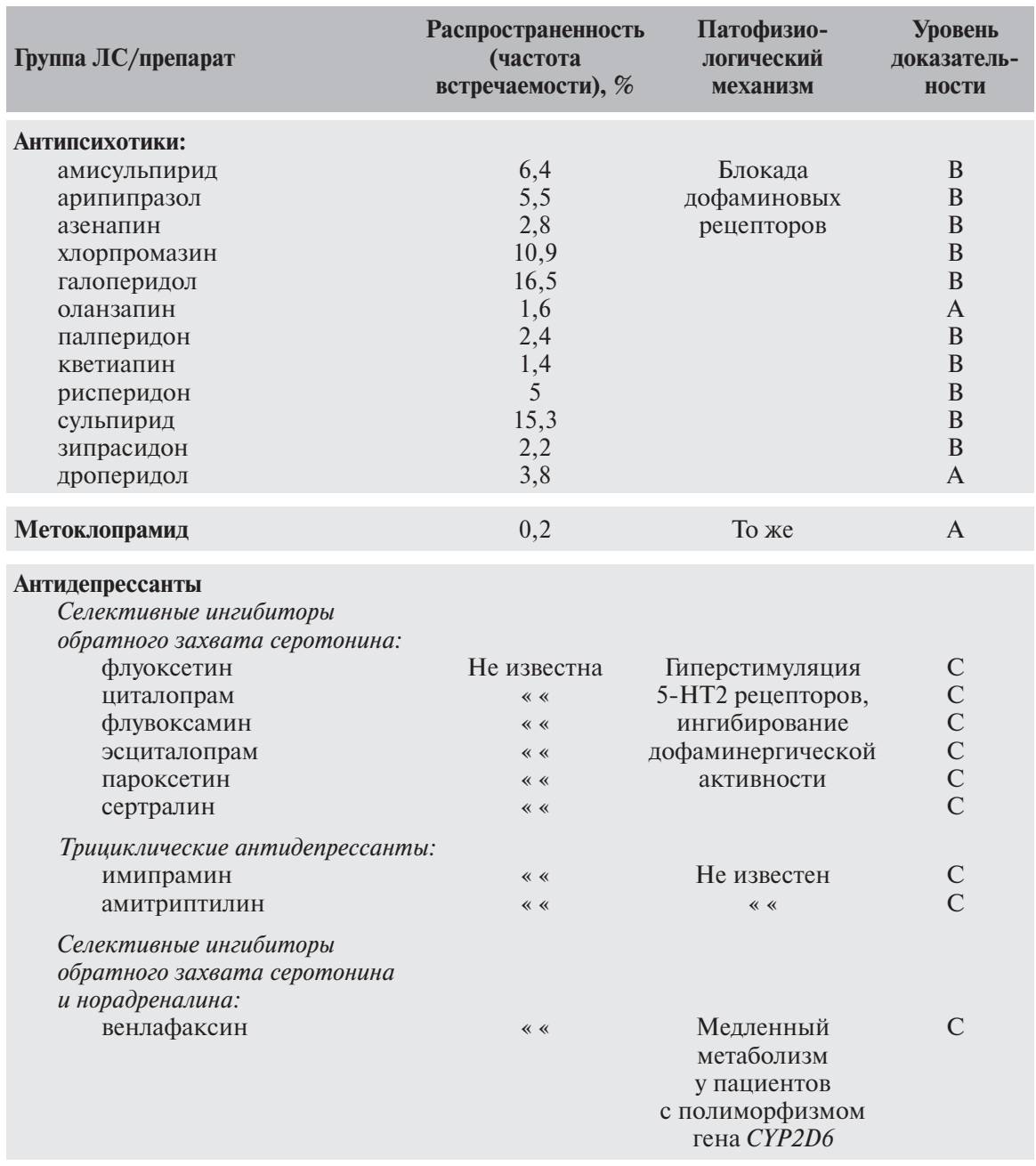

\begin{tabular}{|c|c|c|c|}
\hline \multicolumn{4}{|l|}{ Антиконвульсанты: } \\
\hline карбамазепин & $\ll \ll$ & $\begin{array}{c}\text { Снижение } \\
\text { чувствительности } \\
\text { пресинаптических } \\
\text { дофаминовых } \\
\text { рецепторов }\end{array}$ & $\mathrm{C}$ \\
\hline габапентин & $\ll \ll$ & Не известен & $\mathrm{C}$ \\
\hline ламотриджин & $\ll \ll$ & $\ll \ll$ & $\mathrm{C}$ \\
\hline \multicolumn{4}{|l|}{ Другие ЛС: } \\
\hline метформин & $\ll \ll$ & $\ll \ll$ & $\mathrm{C}$ \\
\hline ламивудин & $\ll \ll$ & $\ll \ll$ & $\mathrm{C}$ \\
\hline ривастигмин & $\ll \ll$ & $\ll \ll$ & $\mathrm{C}$ \\
\hline альбендазол & $\ll \ll$ & $\ll \ll$ & $\mathrm{C}$ \\
\hline
\end{tabular}

Примечания. 5-НТ2 - подсемейство серотониновых рецепторов, т. е. рецепторов, которые связываются с эндогенным нейромедиатором серотонином (5-гидрокситриптамином, 5-HT); CYP2D6 cytochrome P450 2D6 (цитохром P450 2D6). Уровень доказательности [1]: А - одно или более рандомизированных контролируемых клинических исследований; В - нерандомизированные клинические исследования, проспективные обсервационные исследования, когортные исследования, ретроспективные исследования, исследования случай-контроль, метаанализы и/или постмаркетинговое наблюдение; C - наличие как минимум одного опубликованного случая или серии случаев. 
пранолол для лечения эссенциального тремора [23, 26]. ТЛИД также могут возникать при применении ламотриджина [27]. Механизм развития ЛИД на фоне приема антиконвульсантов не до конца ясен. Например, имеются данные о развитии ЛИД в ответ на терапию карбамазепином, как при нормальных, так и при токсических концентрациях ЛС в крови [28].

\section{Другие ЛС}

Имеется публикация, в которой описан клинический случай развития ОЛИД у пациентки с шизофрений при добавлении к ее стандартной терапии (сульпирид 800 мг/сут, клозапин 300 мг/сут) 500 мг метформина [29]. Авторы пришли к выводу, что ЛИД у пациентки развилась из-за межлекарственного взаимодействия метформина и сульпирида. Также описаны случаи развития как ОЛИД, так и ТЛИД у молодых мужчин, получавших ламивудин для лечения гепатита В [30]. Имеется единичное описание ОЛИД на фоне применения пластыря с ривастигмином

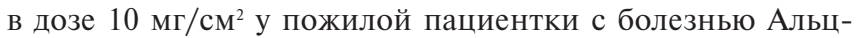
геймера [31]. Также описано развитие ОЛИД у ребенка при одновременном применении альбендазола и цетиризина [32].

\section{Л е че н и е}

При ОЛИД эффективно использование коротким курсом антихолинергических препаратов (бензотропин, дифенгидрамин) [1, 33]. В случае развития жизнеугрожающего состояния (например, ларингоспазма) антихолинергические препараты вводятся внутривенно, при необходимости проводят трахеостомию $[1,33]$. Для уменьшения выраженности тревожных расстройств возможно использование бензодиазепинов $[1,33]$.

При лечении ТЛИД также применяют антихолинергические препараты, атипичные антипсихотики (клозапин, кветиапин), бензодиазепины, мышечные релаксанты (баклофен), препараты, ингибирующие обратный захват дофамина (тетрабеназин). Реже используют амантадин, бетаблокаторы, клонидин, дантролен, леводопу и противоэпи- лептические препараты, такие как леветирацетам, прегабалин, тиагабин и зонисамид [33].

Пациентам с фокальной дистонией (например, цервикальной, ОМД) может быть рекомендовано проведение ботулинотерапии [1]. Этот способ лечения высокоэффективен и безопасен в отношении системных побочных эффектов. В случае неэффективности лечения или при тяжелых формах дистонии используют хирургические методы - интратекальное введение баклофена, глубокую стимуляцию бледного шара, паллидотомию [1].

\section{Про филактика}

Крайне важна для профилактики ЛИД осведомленность врача о возможности данной НПР, особенно при применении ЛС из группы антипсихотиков и метоклопрамида. При подборе ЛС необходимо выбирать препарат с наименьшим риском развития ЛИД.

\section{З а клю че н и е}

Современные демографические тенденции с увеличением продолжительности жизни и старением населения, рост числа больных пожилого и старческого возраста с большим количеством коморбидных заболеваний, проблема полипрагмазии и активное развитие фармацевтического рынка обусловливают повышение риска развития лекарственно-индуцированных синдромов и заболеваний, в том числе ОЛИД и ТЛИД. При этом диагностика лекарственно-индуцированных экстрапирамидных нарушений зачастую осуществляется достаточно поздно в связи с недостаточной информированностью врачей о данной проблеме.

Повышение осведомленности врачей разных специальностей, прежде всего неврологов, психиатров, врачей общей практики, о ЛС, способных вызвать ОЛИД и ТЛИД, будет способствовать оптимизации фармакотерапии, назначению альтернативных ЛС с отсутствием подобной НПР или с минимальным риском ее развития, а также применению адекватных профилактических мер, направленных на предупреждение и снижение риска развития данных экстрапирамидных нарушений.

\section{Л И TEPAT V PA/REFEREN C E S}

1. Tisdale JE, Miller DA, eds. Drug-induced diseases: prevention, detection, and management. $3^{\text {rd }}$ ed. Bethesda, Md.: American Society of Health-System Pharmacists; 2018.

2. Medication-induced movement disorders and other adverse effects of medication. In: Diagnostic and Statistical Manual of Mental Disorders. $5^{\text {th }}$ ed. Arlington, VA: American Psychiatric Association; 2013.

3. Burke RE, Fahn S, Jankovic J, et al. Tardive dystonia: late-onset and persistent dystonia caused by antipsychotic drugs. Neurology. 1982;32(12):1335-46. doi: 10.1212/wnl.32.12.1335

4. Suzuki T, Matsuzaka H. Drug-induced Pisa syndrome (pleurothotonus): epidemiology and management. CNS Drugs. 2002;16(3):165-74. doi: 10.2165/00023210-200216030-00003

5. Stübner S, Padberg F, Grohmann R, et al. Pisa syndrome (pleurothotonus): report of a multicenter drug safety surveillance project. J Clin Psychiatry. 2000 Aug;61(8):569-74. doi: 10.4088/JCP.v61n0805

6. Левин ОС. Лекарственные дискинезии. Современная терапия в психиатрии и неврологии 2014;(3):4-13.

[Levin OS. Drug dyskinesia. Sovremennaya terapiya $v$ psikhiatrii i nevrologii. 2014;(3):4-13 (In Russ.)].

7. Friedman JH, ed. Medication-induced movement disorders. Cambridge: Cambridge University Press; 2015. Chapter 2, Acute dystonia; P. 20-30. doi: 10.1017/CBO9781107588738.003

8. Digby G, Jalini S, Taylor S. Medicationinduced acute dystonic reaction: the challenge of diagnosing movement disorders in the intensive care unit. BMJ Case Rep. 2015 Sep 21;2015:bcr2014207215. doi: 10.1136/bcr-2014-207215
9. Вайман ЕЭ, Шнайдер НА, Незнанов НГ, Насырова РФ. Антипсихотик-индуцированная тардивная дискинезия как серьезная нежелательная реакция при психофармакотерапии шизофрении. Неврология, нейропсихиатрия, психосоматика. 2019;11(4):4-13. doi: 10.14412/2074-2711-2019-4-4-13

[Vaiman EE, Shnayder NA, Neznanov NG, Nasyrova RF. Antipsychotic-induced tardive dyskinesia as a serious adverse effect in the psychopharmacotherapy of schizophrenia. Nevrologiya, neyropsikhiatriya, psikhosomatika = Neurology, Neuropsychiatry, Psychosomatics. 2019;11(4):4-13. doi: 10.14412/2074-27112019-4-4-13 (In Russ.)].

10. Rosebush PI, Mazurek MF. Neurologic side effects in neuroleptic-naive patients treated with haloperidol or risperidone. Neurology. 1999 Mar 10;52(4):782-5. doi: 10.1212/wnl.52.4.782 
11. Bernagie C, Danckaerts M, Wampers M, et al. Aripiprazole and Acute Extrapyramidal Symptoms in Children and Adolescents:

A Meta-Analysis. CNS Drugs. 2016;30(9):807-18. doi: 10.1007/s40263-016-0367-y

12. Martino D, Karnik V, Osland S, et al. Movement disorders associated with antipsychotic medication in people with schizophrenia: an overview of Cochrane reviews and metaanalysis. Can J Psychiatry. 2018;63(11):730-9. doi: 10.1177/0706743718777392

13. Valkova M, Stamenov B, Peychinska D, et al. Metoclopramide-induced extrapyramidal signs and symptoms - brief review of literature and case report. J IMAB. 2014;20(6):539-41. doi: 10.5272/jimab.2014206.539

14. Jo YY, Kim YB, Yang MR, et al. Extrapyramidal side effects after metoclopramide administration in a post-anesthesia care unit - A case report. Korean J Anesthesiol. 2012 Sep;63(3):274-6.

doi: $10.4097 /$ kjae.2012.63.3.274

Epub 2012 Sep 14.

15. Mörkl S, Seltenreich D, Letmaier M, et al. Extrapyramidal reactions following treatment with antidepressants: Results of the AMSP multinational drug surveillance programme. World J Biol Psychiatry. 2020 Apr;21(4):308-16. doi: 10.1080/15622975.2019.1648871.

Epub 2019 Aug 7.

16. Wernicke JF. Safety and side effect profile of fluoxetine. Expert Opin Drug Saf. 2004

Sep;3(5):495-504.

doi: 10.1517/14740338.3.5.495

17. Beyazyüz M, Albayrak Y. Imipramine induced acute dystonia in a child with enuresis nocturna: a case report. Eur Psychiatry.
2013;28(Suppl 1):1. doi: 10.1016/S09249338(13)76911-6

18. Ornadel D, Barnes EA, Dick DJ. Acute dystonia due to amitriptyline. J Neurol Neurosurg Psychiatry. 1992 May;55(5):414. doi: $10.1136 /$ jnnp.55.5.414

19. Hiremath SB, Desai M. Amitriptyline induced cervical dystonia. J Scient Soc. 2016;43(1):38-40. doi: 10.4103/09745009.175458

20. Sonmez I, Kosger F. Venlafaxine-induced acute dystonia: a case report. $J$ Psychiatry Neurol Sci. 2015;28:374-7. doi: 10.5350/DAJPN2015280410

21. Fonseca L, Rodrigues M, Machado A. Psychogenic movement disorder after a venlafaxine-induced dystonia. Mov Disord. 2010 Mar 15;25(4):506-7. doi: 10.1002/mds. 22910

22. Zadikoff C, Munhoz RP, Asante AN, et al. Movement disorders in patients taking anticonvulsants. J Neurol Neurosurg Psychiatry. 2007 Feb;78(2):147-51.

doi: 10.1136/jnnp.2006.100222.

Epub 2006 Sep 29.

23. Pina MA, Modrego PJ. Dystonia induced by gabapentin. Ann Pharmacother. 2005 Feb;39(2):380-2. doi: 10.1345/aph.1E503. Epub 2005 Jan 11.

24. Fadare JO, Owolabi LF. Carbamazepineinduced dystonia, a case report. Neurology Asia. 2009; 14(2):165-6.

25. Bansal S, Gill M, Bhasin C.

Carbamazepine-induced dystonia in an adolescent. Indian J Pharmacol. May-Jun 2016:48(3):329-30. doi: 10.4103/02537613.182879
26. Palomeras E, Sanz P, Cano A, et al. Dystonia in a patient treated with propranolol and gabapentin. Arch Neurol. 2000;57(4):570-1. doi: 10.1001/archneur.57.4.570

27. Marrero-Gonzalez PC, Ruano OL, Catalano G, et al. Dystonia associated with lamotrigine therapy: a case report and review of the literature. Curr Drug Saf. 2014;9(1):60-2. doi: 10.2174/18715249113136660060

28. Strjer R, Strous RD, Bar F, et al. Segmental dystonia as the sole manifestation of carbamazepine toxicity. Gen Hosp Psychiatry. 2002;24(2):114-5. doi: 10.1016/s01638343(01)00177-3

29. Chen WH, Huang WL, Hsieh MH. Metformin-induced acute dystonia in a schizophrenic patient treated with sulpiride and clozapine. Psychiatry Clin Neurosci. 2016;70(8):362-3. doi: $10.1111 /$ pen.12405

30. Song X, Hu Z, Zhang H. Acute dystonia induced by lamivudine. Clin Neuropharmacol. Jul-Aug 2005;28(4):193-4.

doi: 10.1097/01.wnf.0000172367.71932.61

31. Dhikav V, Anand KS. Acute dystonic reaction with rivastigmine. Int Psychogeriatr. 2013;25(8):1385-6. doi: 10.1017/S104161021300029X

32. Yilmaz-Topa Ö, Tuygun N, Akca H, et al. Cetirizine and albendazole induced dystonia in a child. Turk $J$ Pediatr. Jul-Aug 2015;57(4):407-8

33. Bhidayasiri R, Fahn S, Weiner WJ, et al. Evidence-based guideline: treatment of tardive syndromes: report of the Guideline Development Subcommittee of the American Academy of Neurology. Neurology. 2013;81:4639. doi: 10.1212/WNL.0b013e31829d86b6

Поступила/отрецензирована/принята к печати Received/Reviewed/Accepted 1.07.2020/10.08.2020/19.08.2020

\section{Заявление о конфликте интересов/}

Исследование не имело спонсорской поддержки. Конфликт интересов отсутствует. Авторы несут полную ответственность за предоставление окончательной версии рукописи в печать. Все авторы принимали участие в разработке концепци статьи и написании рукописи. Окончательная версия рукописи была одобрена всеми авторами.

\section{Conflict of Interest Statement}

The investigation has not been sponsored. There are no conflicts of interest. The authors are solely responsible for submitting the final version of the manuscript for publication. All the authors have participated in developing the concept of the article and in writing the manuscript. The final version of the manuscript has been approved by all the authors.

Остроумова T.M. https://orcid.org/0000-0003-1499-247x

Толмачева В.A. https://orcid.org/0000-0002-8115-2668

Остроумова О.Д. https://orcid.org/0000-0002-0795-8225

Парфенов В.A. https://orcid.org/0000-0002-1992-7960 